\title{
María Pizarro: posesión demoníaca y los nuevos controles epistémicos en el Perú colonial
}

María Pizarro: demoniac possession and the new epistemic controls in colonial Peru

\author{
Rubén Quiroz Ávila \\ Universidad Nacional Mayor de San Marcos \\ Contacto: rquiroz@unmsm.edu.pe
}

\begin{abstract}
Resumen
Se plantea una lectura de las formas del mal en las claves teológicas y filosóficas del Perú colonial del siglo XVI. El caso fundacional de María Pizarro como un cuerpo textualizado sobre los límites de la colonización y sus narrativas legitimadoras. Además, se construye un sistema discursivo de demonización que configura el nuevo orden disciplinario. De esa manera se instalan los nuevos sistemas de control de la epistemología y, con ello, la administración eficaz de los intentos revolucionarios coloniales.

Palabras clave: María Pizarro, Perú colonial, posesión demoníaca, rebeliones peruanas.
\end{abstract}

\begin{abstract}
A reading of the forms of evil is proposed in the theological and philosophical keys of seventeenth-century colonial Peru. The founding case of María Pizarro as a textual body on the limits of colonization and its legitimating narratives. In addition, a discursive system of demonization is constructed and configures the new disciplinary order. In this way new systems of control of epistemology are installed and, with it, effective management of colonial revolutionary attempts.
\end{abstract}

Keywords:María Pizarrro, Colonial Peru, Demonic possession, Peruvian rebellions.

El siglo XVI peruano, con los niveles de transformación cultural en ciernes, tiene un abanico tanto de sucesos como de líneas teóricas que nos dan cuenta de una tensa eclosión y su complejidad naciente. En torno a ello hay un evento que dispara las redes de discusión teológica en el Perú colonial. En este caso es la génesis sobre la cual se van desenvolviendo vehementes debates 
políticos y teológicos. En 1568 una joven mujer analfabeta ${ }^{1}$, María Pizarro, es considerada poseída por una serie de demonios y seres extraños. Por ello es vigorosamente exorcizada y luego, ante el fracaso de ello, procesada por la Inquisición. Murió en prisión en 1573. Pizarro, quien había pasado brevemente por un monasterio, dio inicio a una cadena de sucesos que agitaron nerviosamente la capital del virreinato. Su posesión demoníaca comenzó a detectarse a mediados de 1568. En una época en que la lucha contra lo demoníaco era un vector fundamental, era evidente que la importancia del caso iba in crescendo. Comenzó con un dolor de cabeza de tal magnitud que incluso la extremaunción parecía inevitable. Una dolencia física fue transformándose en un universo de plétora teológica. Un hermano suyo, Martín Pizarro, quien tenía conocidos en la estrenada Compañía de Jesús, solicitó el apoyo de la Orden para acompañarla espiritualmente y rezaran por su alma (Millar, 2007). Sin embargo, al ser evaluada por el Provincial de la Compañía, Jerónimo Ruiz de Portillo y Luis López, quien cumpliría un papel fundamental en el caso De la Cruz, se determinó su estatus de poseída. Pero su inexperiencia en exorcismos los llevó a solicitar ayuda a los dominicos, más curtidos en el asunto. Este grupo de predicadores citados estuvo conformado por fray Alonso Gasco, fray Alonso de Santis y fray Juan de los Ángeles. Quien se integró más bien tardíamente fue fray Francisco de la Cruz, el célebre heresiarca quemado por la Inquisición.

Jesuitas y dominicos, en junta, deciden proceder al exorcismo en secreto ya que la expectativa en la ciudad, tensada por atmósferas de idolatría, herejías y evangelización intensas, era inmensa y podría causar un caudal imprevisto de percepciones ${ }^{2}$. Consecuencia mediática que, a pesar de esos esfuerzos encubiertos, no pudo evitarse, por cierto. De ese modo, la noticia de una patente posesión se convirtió en el centro de atención limeña. Ahora el demonio tenía forma de mujer.

Así, Portillo y López eran quienes tenían inicialmente la mayor carga en el exorcismo iniciado. Alonso Gasco transcribía las visiones de María, al igual que fungía de su confesor personal. Ello le permitió acceder a información 
considerada hermética, la cual iba tejiendo los cruces discursivos cada vez más enrevesados. Gasco, destinado a Quito durante el proceso a la endemoniada, luego se autoinculpará y agudizará con ello el drama conspirativo de De la Cruz. Además, quemará inútilmente las transcripciones que hizo de las visiones de Pizarro, dictadas por santos y ángeles a través de ella, y será la otra víctima mortal de la Inquisición en el auto de fe de 1578. Son estos teólogos, de los más brillantes en ese momento crítico, quienes participaron durante años en dicho sumario exorcista. Además, entre ellos, se carteaban en lenguaje cifrado, lo cual indica el cuidado y la metodología misteriosa que usaban para su comunicación más vital:

[...] confiesa que escrivió a fray Pedro de Toro, de esta ciudad, tres cartas cerca destas cosas y en una dellas, en cierta cifra que ellos se entendían y tenían su abecedario, le escribió que él y el dicho fray Francisco de la Cruz, eran predestinados. (Medina, 1887, p. 60)

Jerónimo Ruiz del Portillo formó parte del primer contingente jesuita llegado al Perú. Con mucho prestigio religioso y social, además con evidente influencia en la construcción del nuevo modelo de conversión, fue comisionado para liderar en Potosí, cuya concentración poblacional parecida a la de Juli favorecía la difusión del nuevo sistema de creencias. Sin embargo, este encargo no terminó bien, como lo atestigua el proceso que le abrieron por abandono de sus funciones ${ }^{3}$. Pero es su travesía de España a Lima aquello que lo va pintando como un hombre profundamente preocupado ${ }^{4}$ por activar rápidamente la evangelización:

Predicaba el padre Portillo y cada domingo y los días de fiesta, y aun en otros tiempos contra los vicios que reinaban en la ciudad, entre los cuales eran de mayor escándalo las modas pecaminosas y los bailes poco decentes. Mucho consiguió su celo con la gracia divina, y después de algunos meses se podía conocer una sincera enmienda en muchas personas. No se contentaron los predicadores con desarraigar el mal, sino que también aconsejaban la práctica de la virtud con la frecuencia de Sacramentos, especialmente la comunión frecuente. Esta frecuencia era casi totalmente desconocida, apenas si los fieles comulgaban una vez al año, o cuando se podía ganar algún jubileo o 
indulgencia plenaria. Los padres consiguieron en muchas personas la comunión varias veces en el año, mensual y aun semanal; con grande provecho de las almas. Por ser el padre Portillo muy devoto del Santísimo Sacramento promovió con grande ardor esta devoción, especialmente en la fiesta del Corpus, que procuró se celebrase con toda solemnidad, no sólo en el día mismo de la fiesta, pero además durante toda la Octava. Para lograr este fin tuvo el Santísimo expuesto en nuestra iglesia todos los días de la Octava con solemne reserva por la tarde [...]. (Jouanen, 1941, p. 14)

El jesuita Luis López es otro personaje al que debe prestarse muchísima atención y seguirle el rastro. Hay una ruta que atribuye a López ${ }^{5}$ también una estratégica participación en la constitución de la tesis temprana emancipadora, por lo que fue acusado de traición y sedición contra el rey, lo cual amplia a otro nivel la probable conjura independentista. Es conveniente recalcar su relación como maestro con los jesuitas en formación, como el mestizo Blas Valera, de crucial importancia en el escenario teórico que sigue inmediatamente el Perú ${ }^{6}$. López fue procesado por la Inquisición desde 1579 hasta 1582 . Se le consideraba autor de unos cuadernos que arguiían la ilegitimidad del gobierno hispánico y un consumado antirregalista. Atacaba la base del derecho de posesión que el papado había ofertado. Es decir, la estructura misma del derecho de conquista promovida y validada por las bulas pontificias. Fue expulsado a España donde muere en Sevilla el año de 1599.

\section{La presencia del diablo}

La figura y presencia del diablo ha sido estudiada desde muchos vértices y, durante el lapso de tiempo que estamos presentando, tenía una exhibición cardinal. Es decir, es medular detenernos tanto en la conceptualización del diablo como en sus representaciones, ya que el enfrentamiento de los poderes divinos versus los diabólicos en la etapa medieval ${ }^{7}$ era absolutamente real (Zamora, $2003)^{8}$. El propio universo como tal era un inmenso campo de batalla entre el bien y el mal. La guerra contra el diablo había que darla a cada instante. De ese modo los exorcismos, con toda la ceremonia bélica, esfuerzos retóricos y físicos que suponían, era un modo indudable de hacer frente al mal apenas manifestado y 
salvar al alma atormentada. Los demonios iban colonizando todo el cuerpo de María Pizarro y se iban concentrando en partes de ella: la cohorte diabólica, numerosa, múltiple y de todas las categorías que según su jerarquía se distribuían en el mapa corporal femenino. El padre nuestro, oración por excelencia para expulsar demonios, era un arma poderosa, igual que el chorreo del agua bendita como insumo ineludible. La palabra dicha, evocada, lanzada, juega un rol clave. La jerga y terminología de agravios contra los demonios además de gritados son también muchas veces procaces. Cada frase mentada, dicción aludida, tenía que ser agresiva y cruel. También las admoniciones no eran nada pacíficas (Amorth, 2010).

Los dominicos como lectores asiduos y emblemáticos de Tomás de Aquino seguían sus interpretaciones de la figura del diablo y su conceptualización del mal. Según las claves tomistas, el mal es una desviación respecto al bien (Aquino, 1950-60, parte I, cuestión 63). Todo lo que existe es bueno inherentemente, ya que procede de Dios ${ }^{9}$. Base epistémica también de la bondad natural de los indios y que demuestra la creación perfecta y bienhechora de Jehová y, también, evidentemente del diablo. Satanás no nació malo. Su naturaleza es angelical. Este eligió alejarse de la divinidad celestial, por lo tanto, en su libre albedrío, incorpóreo, elección completamente intelectual, ya que al no tener cuerpo ningún conocimiento proviene de él, intenta atraer y seducir a todos hacia el mal. Para el Doctor Angélico el diablo no es la causa del mal pero sí quien lo promueve, estimula y requiere. Cada pecador suma en su cruzada contra Dios. Su ejército de esa manera se incrementa. Por ello puede temporalmente poseer un cuerpo humano así como también puede abandonarlo, es más, se debe expulsarlo. De tal forma el exorcismo adquiere una dimensión guerrera directa. Enfrentarse a la corte demoníaca es un campo de batalla deseado y un privilegio. Así adquiere sentido el imperativo bíblico de Mateo 12:28, "Pero si yo por el Espíritu de Dios echo fuera los demonios, ciertamente ha llegado a vosotros el reino de Dios". Jesús los había expulsado de manera contundente y, ese poder, se lo había extendido a sus apóstoles y sus seguidores. Hay que vencer siempre al 
diablo. El exorcismo es una preciosa oportunidad para ello y una demostración de poder contra Satán. Es que el diablo, en esa lógica, no es una figura literaria, es plenamente real y existe.

Al parecer se usaba el Malleus maleficarum de Heinrich Kramer y Jakob Sprenger, publicado en 1490, y como manual el Liber Sacerdotalis (1523), del dominico Alberto Castellani, de amplia difusión para los casos de exorcismo ${ }^{10}$. Por ello los protocolos estaban bosquejados aunque no rigurosamente estandarizados en ese momento. Asimismo, el uso del pater noster tridentino, que no es otro más que la reafirmación del niceno-constantinopolitano, como herramienta enérgica antidiabólica y recordatorio teológico manifiesto a los demonios a ser desalojados. Las oraciones inician la cruzada. A través del exorcista, la Iglesia se manifiesta e imperativamente comienza el duelo guerrero $^{11}$. En eso es rotundo el final de la plegaria doctrinaria: Et ne nos inducas in tentationem, sed libera nos a malo. Amen. Eso. Liberarse del mal. Además, el poder de Cristo en ello es imprescindible para el triunfo de la admonición. Con precisión lo indica el evangelio de San Marcos, capítulo 1, ante un conocido caso de posesión bíblica:

25 Pero Jesús le reprendió, diciendo: iCállate, y sal de él!

26 Y el espíritu inmundo, sacudiéndole con violencia, y clamando a gran voz, salió de él.

27 Y todos se asombraron, de tal manera que discutían entre sí, diciendo: ¿Qué es esto? ¿Qué nueva doctrina es esta, que con autoridad manda aun a los espíritus inmundos, y le obedecen?

La condición inmaterial del diablo facilita que pueda optar por aparecer de las maneras físicas que considere (Balducci, 1990). Se sirve de un cuerpo. Puede ser un súcubo, íncubo, guapo galán o bellísima mujer, con diversas formas de animales, de colores, preferentemente el negro y el rojo, además de los consabidos cuernos, claro. La representación figurativa tenía un determinado catálogo y también sus límites plásticos conocidos. El demonio tampoco puede ser de cualquier manera. Tiene una organización12. Por ello, reconocer el 
nombre de los demonios es fundamental pues señala su debilitamiento. En tanto se resistan a decir o revelar sus nombres, es signo aún de su fortaleza y hay que reiterar las técnicas exorcistas. En tal sentido, hay que exigirles que digan su nombre. Ubicarlos nominalmente se considera el inicio de su derrota. El procedimiento de liberar del mal a la persona toma muchas sesiones y fue, para los exorcistas coloniales, sumamente agotador, al parecer.

Hay un referente icónico que conjetura el tono de los mensajes. Dejan de ser un elemento pasivo e inocuo para transformarse en preceptos celestiales. La transferencia del mensaje y su autoridad depende de quien la emite. Así, además de saber qué demonio es el que habla, es indispensable conocer el inventario de personajes que también formulan recados con diversos objetivos. Esas figuras son los ángeles, arcángeles o la misma Virgen María. Sin embargo, una imagen escolta permanentemente a María Pizarro. Esa figura es la del ángel guardián, es decir, su custodio personal, que se supone todos los humanos tienen y que Dios ha designado para su protección. Se dice en Éxodo 23:20, "He aquí yo envío mi Ángel delante de ti para que te guarde en el camino, y te introduzca en el lugar que yo he preparado". Además, los seguidores del aquinatense manejan la tesis de la custodia angelical tal como lo señala en la respuesta al artículo 2: "A cada hombre, ¿le corresponde o no le corresponde un ángel custodio?”, de la Suma Teológica en la parte I, cuestión 113 (Aquino, 1950-1960):

Ángeles diversos están destinados a la custodia de los diversos hombres custodiados. El porqué de esto radica en que la guarda angélica es una ejecución de la divina Providencia sobre los hombres. Pero la providencia que Dios tiene sobre los hombres es distinta de la que tiene sobre las otras criaturas corruptibles, por tener el hombre y las demás criaturas distinta relación a la incorruptibilidad, pues los hombres no sólo son incorruptibles en cuanto a su especie común, sino también en cuanto a sus propias formas singulares, que son las almas racionales, lo cual no puede decirse de las otras cosas corruptibles. Es evidente, por otra parte, que la providencia de Dios se ocupa principalmente de aquellas cosas que permanecen perpetuamente; en cambio, de las cosas transitorias se ocupa en cuanto las ordena a las perpetuas. Así, pues, la providencia de Dios está en relación con cada uno de los hombres en particular como está 
en relación con cada uno de los géneros o especies de las cosas corruptibles. Ahora bien, según Gregorio, diversos órdenes angélicos son destinados a los diversos géneros de cosas. Ejemplo: Las Potestades, a ahuyentar a los demonios; las Virtudes, a obrar milagros en las cosas corpóreas; y es también muy verosímil que estén destinados diversos ángeles de un mismo orden a la guarda de las diversas especies de seres. Por lo tanto, es también muy conforme a razón que sean destinados diversos ángeles en particular para la guarda de los diversos nombres.

Este ser angelical tiene como misión primordial salvaguardar al individuo en su camino a la salvación. Entonces tiene una labor personalísima muy dura y permanente. En este caso va a cumplir un rol que direcciona los acontecimientos. Es decir, no es lo mismo una posesa en la cual es solo la corte demoníaca quien se anuncia y establece la querella, sino la aparición de visiones donde se expresan más bien personajes celestiales.

De ese modo, la estratagema exorcista adquiere otro cariz. Es verdad que, para los dominicos y jesuitas, como lo sostiene toda la tradición bíblica, el demonio es muy sagaz y un experto embaucador. Por lo tanto, para saber las diferencias del engaño hay que acudir a la lucidez y una minuciosidad histórica. Sin embargo, los exorcistas ahora revisan sus propósitos y se atienen a reparar en la potestad de los emisores. De ese modo, caída la barrera de solo expulsar demonios, la atención activa exégesis proféticas y pesquisas teológicas.

El corpus bíblico reconoce tres ángeles —Miguel, Gabriel y Rafael—, cuyo supremo valor se notará en tanto mensajeros de indispensables noticias para la humanidad. Y quien aparece reiteradamente es el arcángel Gabriel. Este mensajero es sumamente especial ya que su presencia y anunciación de buenas nuevas ha sido fundamental para la historia en general. Anunció al anciano sacerdote Zacarías la llegada de un profeta que divulgaría el giro hacia Dios a través de su hijo en la Tierra. Cito de Lucas 1:13, "Pero el ángel le dijo: Zacarías, no temas; porque tu oración ha sido oída, y tu mujer Elisabet te dará a luz un hijo, y llamarás su nombre Juan”. Semejante anuncio iba a conmover el futuro. Por lo tanto, bajo esa línea teleológica la aparición del profeta fue previa a la aparición 
del héroe principal. Además, pregona su nombre. Y con ello remarca su misión: Lucas 1:19: "Respondiendo el ángel, le dijo: Yo soy Gabriel, que estoy delante de Dios; y he sido enviado a hablarte, y darte estas buenas nuevas". De ese modo, Juan Bautista, estaba previsto desde la planificación divina. El maravilloso emisario notificaba un hecho indefectible. La otra aparición espectacular es ante María para darle a conocer el nacimiento de Jesús. Cito de Lucas 1:

26 Al sexto mes el ángel Gabriel fue enviado por Dios a una ciudad de Galilea, llamada Nazaret,

27 a una virgen desposada con un varón que se llamaba José, de la casa de David; y el nombre de la virgen era María.

28 Y entrando el ángel en donde ella estaba, dijo: iSalve, muy favorecida! El Señor es contigo; bendita tú entre las mujeres.

29 Mas ella, cuando le vio, se turbó por sus palabras, y pensaba qué salutación sería esta.

30 Entonces el ángel le dijo: María, no temas, porque has hallado gracia delante de Dios.

31 Y ahora, concebirás en tu vientre, y darás a luz un hijo, y llamarás su nombre Jesús.

32 Este será grande, y será llamado Hijo del Altísimo; y el Señor Dios le dará el trono de David su padre;

33 y reinará sobre la casa de Jacob para siempre, y su reino no tendrá fin.

Gabriel, además de anunciar buenas nuevas es también el emisario del fin del mundo. Así fue su aparición ante el profeta Daniel. Anoto de Daniel 8:

116 Y oí una voz de hombre entre las riberas del Ulai, que gritó y dijo: Gabriel, enseña a éste la visión.

17 Vino luego cerca de donde yo estaba; y con su venida me asombré, y me postré sobre mi rostro. Pero él me dijo: Entiende, hijo de hombre, porque la visión es para el tiempo del fin.

18 Mientras él hablaba conmigo, caí dormido en tierra sobre mi rostro; y él me tocó, y me hizo estar en pie.

19 Y dijo: He aquí yo te enseñaré lo que ha de venir al fin de la ira; porque eso es para el tiempo del fin.

Bajo esa argumentación, los mensajes de Gabriel son esenciales. Considerando su formidable jerarquía, ergo, se convierte en protagonista de las 
ahora visiones de María. Una de las visiones más considerables es su desposorio con Cristo: "Confiesa cómo la dicha doña María. le dixo a él y a fray Francisco aquella vision quando se avia desposado con Jesuchristo y que todo lo creyan" (Medina, 1887, p. 194). Vinculación que debería originar un grado de autoridad absolutamente distinta. Este ceñía la situación a una línea mística. Recordemos que en años posteriores, en 1617, Rosa de Lima iba a ser la esposa más célebre13 en estas nupcias espirituales. Entonces, la raya que separaba una posición mística y la acusación por alumbradismo ${ }^{14}$ era totalmente endeble. Así es que Pizarro, como es coherente con los resultados, no fue leída como una esposa de Jesucristo. El cuestionamiento era esquemático. Según el orden de la vida mística esta se divide en: penitente, iluminativa y unitiva, donde es finalmente el abrazo cumbre con el Señor. No hay indicios en la documentación que consultamos donde se señale que María Pizarro haya pasado por esas etapas.

De ese modo, su fortaleza mayor se centra en que es un instrumento corporal para que el ángel Gabriel comunicara cuestiones significativas:

\begin{abstract}
Cuenta cómo decía ella que vía aquel armado y cómo la hacía muchos buenos sermones, cómo le avían conjurado y avía dicho que era el ángel de la guarda, y que la dicha doña María le avia dicho que vía en su frente del dicho fray Pedro un Jesus de oro y encima un escudito con las armas de sancto Domingo; y dice, asimismo, cómo la dicha decía que via, sin el armado, otros sanctos, que eran sanct Dionicio, sanct Sebastian, y que el armado tenya una varita de oro en la mano, y que despues le vió en figura de ángel. (Medina, 1887, p. 61)
\end{abstract}

Ante la legitimidad de la presencia del ángel mensajero, el discernimiento de las señales requiere otra evaluación. De ese modo, María Pizarro es examinada ahora desde otra perspectiva. Ya no es una mujer posesa sino un dispositivo celestial. Por lo tanto, lo que se pueda decodificar de los mensajes divinos sirve para acoplarlos con el clima histórico y resemantizar los hechos. Entonces, el martirio de San Dionisio —el santo sin cabeza—, uno de los primeros en padecer terriblemente las persecuciones contra los cristianos en el siglo III, reaparece como signo de heroísmo en el sufrimiento. A ello se acopla 
perfectamente la figura de San Sebastián, célebre en la iconografía católica por su trágica imagen donde es atravesado por sinnúmero de flechas por su elección religiosa también en el siglo III. Así, con esas apariciones coloniales, se conecta a un martirologio oficial y mayor.

Y a dicha doña María Pizarro se prendió y secuestraron sus bienes y presa, en las confesiones que haze, dize que un día acabándola de exorcizar fray Alonso Gaseo, avía visto dos hombres vestidos con albas blancas, el uno tenía un rrétulo en la mano y el otro una mitra en la cabeza y traya la cabeza cortada en las manos, el qual decia que era Sant Dionisio, y otro desnudo y lleno de heridas y las manos atadas, que era San Sebastian y San Josep, y los dos de las albas decian que eran ángeles, y el uno decia que era Gabriel, embaxador de Nuestra. Señora, y el que traya un rrétulo en la mano le avia dicho que le enbiaba Jesuchristo por su ayo, y gue a Sant Dionisio pusieron una silla muy alta con muchos terciopelos y un estrado, y lo pusieron el de las manos atadas y el otro ángel, y estando así sentado, le avia echo un sermón, diciéndola que Dios la quería mucho porque le avia costado mucho y por ninguna cosa que hiciese no desconfiase de Dios, y que esto no lo avia visto nadie sino ella, que hablaría con ellos como si hablara con otras personas. (Medina, 1887, pp. 68-69).

Sin embargo, la aventura religiosa recién empezaba. Los comunicados angelicales, los mensajes celestiales, las profecías, las elucubraciones teológicas, las discordias teóricas inaugurales, las incógnitas cada vez más cuestionadoras del statu quo van a seguir su conflictivo camino que llegará a su clímax con la relectura revolucionaria que plantea Francisco de la Cruz. Así, el cuadro de las contiendas teóricas va adoptando mayor complejidad y también una feroz respuesta del Imperio. De ese modo, el factor María Pizarro como disparador de la componenda teórica posterior, nos da hilos conductores ineludibles para comprender con mayor propiedad los procesos de resistencias nacientes a la imposición colonial.

\footnotetext{
Notas

11 " "...] rudo y corto entendimiento y no aplicado a saber ni aún del oficio de mujeres que es labrar y coser, y así no sabe leer, ni tañer, ni otros ejercicios"; amén de endosarle otro cúmulo de defectos, como el ser "mal inclinada, impaciente, presuntuosa, envidiosa y mentirosa" (Millar, 2007, p. 382).
} 
12 "Destaquemos que era muy complicado para la gente de la cercana comunidad de María demostrar contundentemente que sus argumentos eran irracionales o teológicamente erróneos. El imaginario usado, en ese caso, estaba en perfecta sintonía con las expectativas y sensibilidades de los habitantes de Lima." (Redden, 2008, p. 48; traducción del autor).

${ }^{13}$ Véase el proceso inquisitorial de 1587: "Proceso criminal contra el padre Jerónimo Ruiz del Portillo, jesuita, vecino de Potosí (Bolivia), comisario del Tribunal de la Inquisición en la dicha ciudad, por dejación de funciones. Fue denunciado por Antonio Escobar, mercedario". Código de referencia: ES.28079.AHN/1.1.11.4.14.1//INQUISICIÓN,1646, Exp. 4.

${ }^{14}$ Envió en 1573 al Cuzco a Alonso de Barzana, Bartolomé de Santiago y Blas Valera, quienes dominaban el quechua y el aimara, para facilitar la evangelización. Valera se ordenó sacerdote en 1574 , a su llegada a la capital andina.

${ }^{15}$ Jiménez de la Espada, primero, y luego Pierre Duviols, le atribuyen la autoría del anónimo De las costumbres antiguas de los naturales del antiguo Pirú (1594). Otros investigadores como Manuel Gonzales de la Rosa, José Toribio Polo y León Lopetegui lo adjudican a Blas Valera. Es considerado como uno de los enigmas más importantes de las crónicas postoledanas (Albertin, 2008). En todo caso, es una categórica respuesta a Polo de Ondegardo y, según el anónimo, su influencia nefasta en las crónicas posteriores. Además, minuciosamente rebatía las tesis antropofágicas sobre los peruanos.

${ }^{16}$ Refiero un durísimo debate sobre las vinculaciones de una posible conspiración jesuita. Esto ha llevado a sostener a Laura Laurencich que la Nueva Corónica y Buen Gobierno no es un texto producido por Guaman Poma sino por Blas Valera. Esta tesis alucinante ha sido rebatida contundentemente por Rolena Adorno $(1998,2000)$ y otros especialistas.

17 "Nunca antes la figura del diablo había estado tan presente en la Historia occidental como durante los siglos XVI y XVII y, en lo sucesivo, jamás lo volverá a estar. En el periodo que discurre entre 1550 y 1680 tomó forma un modelo diabólico desesperante, mordaz y angustioso, condicionado por las circunstancias que golpearon a una Europa rasgada a causa de las guerras de religión” (Zamora, 2008, p. 411).

${ }^{18}$ Russell sostiene brillantemente: "El mal real, absoluto exige que lo veamos. Nos amenaza a cada uno y a todos. Si no lo examinamos corremos grave peligro. Y de ningún modo podemos trivializarlo. Si no se le percibe como la personificación del mal real, el diablo pierde todo sentido" (Russell, 1995, p. 18).

${ }^{19}$ "Todo lo que existe, por el simple hecho de existir, tiende naturalmente a algún bien, ya que procede de un principio bueno" (Aquino, 1950-60, Art. 4, respuesta a las tres objeciones).

${ }^{110}$ En 1614, el Rituale Romanum de exorcismos fue autorizado por el papa Paulo V y convertido recién en manual oficial.

111 "El proceso de formación de la demonología quedó así completado. El mal, tras su caída, se fragmentó en una amplia serie de representaciones tangibles y visibles que eran clasificadas en una jerarquía que tenía su correlato no solo con la angélica, sino también con la feudal. Todos ellos dispusieron de poderes sobrenaturales y excepcionales, a través de los que rindieron pleitesía absoluta a su señor, Satanás” (Zamora, 2008, p. 389).

${ }^{112}$ Es en Acerca de la jerarquía celeste de Pseudo-Dionisio Areopagita (siglos V-VI), donde se describe la estructura de la sociedad angelical.

${ }^{113}$ El antecedente más visible en la tradición cristiana es la dominica Santa Catalina de Siena (1347-1380), quien también se había casado con Cristo. 
${ }^{114}$ La lectura de un mesianismo apocalíptico en mujeres fue combatida de nuevo por la Inquisición limeña en el siglo XVII, luego del caso Rosa de Lima. Además, se narra una situación interesante en esta línea de relectura del Apocalipsis en América. Cito: "Aquí mencionaba que tras la muerte de Rosa la había visto glorificada unas cincuenta veces, cercada de cientos de ángeles, con una palma en la mano y sembrado su cuerpo de rosas blancas y rojas. Antes de morir, ella le había prometido pedirle a Dios mercedes para él, y Del Castillo le atribuía a ella todos sus nuevos dones visionarios y proféticos con los que pretendía haber podido descifrar los vaticinios proféticos del Antiguo y del Nuevo Testamento a la luz del Apocalipsis" (Mujica, 2001, p. 523).

\section{Referencias bibliográficas}

Adorno, R. (1998). Criterios de comprobación: el manuscrito Miccinelli de Nápoles y las crónicas de la conquista del Perú. Anthropológica, 16, 369394.

Adorno, R. (2000). Contenidos y contradicciones: la obra de Felipe Guaman Poma y las aseveraciones acerca de Blas Valera. Ciberletras: Revista de crítica literaria y de cultura, 2, [s. p.]. Recuperado de http://www.lehman.cuny.edu/ciberletras/v01n02/Adorno.htm

Albertin, Ch. (Ed.). (2008). De las costumbres antiguas de los naturales del antiguo Pirú. Madrid, España: Iberoamericana Vervuert.

Amorth, G. (2010). Memorias de un exorcista. Mi lucha contra Satanás. Barcelona, España: Urano.

Aquino, T. (1950-1960). Suma Teológica. Madrid, España: Biblioteca de Autores Cristianos.

Balducci, C. (1990). El diablo existe y se puede reconocerlo. Bogotá, Colombia: Ediciones Paulinas.

Jouanen, J. (1941). Historia de la Compañía de Jesús en la Antigua Provincia de Quito: 1570-1774, tomo I. Quito, Ecuador: Editorial Ecuatoriana.

Medina, J. T. (1887). Historia del tribunal del Santo Oficio de la Inquisición de Lima (1569-1620), tomo I. Santiago, Chile: Gutenberg.

Millar, R. (2007, julio-diciembre). Entre ángeles y demonios. María Pizarro y la inquisición de Lima 1550-1573. Historia, 40(2), 379-417.

Mujica, R. (2001). Aproximaciones apocalípticas a los "desposorios místicos" de Santa Rosa de Lima. Anuario de Historia de la Iglesia, 10, 522-529. Recuperado de http://www.redalyc.org/articulo.oa?id =35501049

Redden, A. (2008). Diabolism in Colonial Peru, 1560-1750. Cambridge, EE. UU.: Pickering \& Chatto.

Russel, J. B. (1995). Lucifer. El diablo en la Edad Media. Barcelona, España: Editorial Laertes.

Zamora Calvo, M.J. (2003). Posesiones y exorcismos en la Europa barroca. Garoza: revista de la Sociedad Española de Estudios Literarios de Cultura Popular, 3, 
Rubén Quiroz Ávila

213-229.

Zamora Calvo, M. J. (2008). Las bocas del diablo. Tratados demonológicos en los siglos XVI y XVII. Edad de oro, 27, 411-445. 